\title{
ACCURACY OF DIAGNOSIS ON DEATH CERTIFICATES COMPARED WITH THAT IN HOSPITAL RECORDS
}

\author{
BY \\ M. R. ALDERSON AND T. W. MEADE \\ M.R.C. Social Medicine Research Unit, The London Hospital
}

Mortality statistics have been available in Great Britain since 1839, but many have drawn attention to inaccuracies which lessen their usefulness (Farr, 1839; Stocks, 1935; Registrar General, 1954). Studies of the accuracy of death certificates have been carried out in three main ways:

(1) By comparison with autopsy findings (Jackson, 1896; Cabot, 1912; Swartout, 1934; Heasman, 1962);

(2) The evidence for the diagnosis on the certificate has been assessed by a questionnaire addressed to the certifier (McKenzie, 1956; Morris, 1964; Moriyama, Baum, Haenszel, and Mattison, 1958);

(3) The wording of the death certificate has been compared with the clinical diagnosis obtained from a study of clinical case notes (MacDonald, 1938; Dorn and Horn, 1941 ; Alderson, 1965).

Over the past few years about half the deaths in England and Wales have occurred in hospital, and for these the case-summary sheet of the hospital notes readily provides an alternative to the statutory death certificate as a source of information on the "underlying cause". The Oxford Record Linkage Study (ORLS) brings together, in a series of personal cumulative files, a number of medical records for a whole population, including abstracts of all spells of in-patient treatment and all death certificates. The principal condition treated in hospital, and the underlying cause of death obtained from the death certificate, are among the items coded; the coding was done in 1962 by clerical staff employed in the study (Acheson, 1964). This enabled one of the authors (M.R.A.) to examine the coding of these two items for the 1,216 deaths occurring in hospital in 1962 in the Study Area to see to what extent the two codings differed and to identify factors associated with discrepant codings. The population in 1962 (about 325,000) consisted of the residents of the County Borough of Oxford, Oxfordshire (except Henley M.B. and R.D.C.), Abingdon Borough, and Abingdon Rural Area; it is served by thirty hospitals who co-operated in the study.
The codings were used for the comparison, rather $\overline{0}$ than the actual wording of the entries on the hospitals notes and death certificates, as this enabled punchi cards and a tabulator to be used. This introducesthe possibility of coding errors affecting the compari- $N$ son, but check of a sample of 42 records in whicho there was a discrepancy between the two diagnoses showed no evidence of coding errors.

\section{Comparison of Coding}

The 1,216 deaths were initially grouped according to the International Statistical Classification of $\overrightarrow{0}$

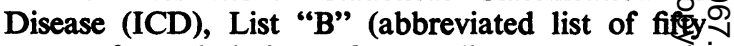
causes for tabulation of mortality, e.g. B 18 लैं "Malignant Neoplasms"). The coding for 61 per ceñ. of the deaths fell within the same list number for both the principal condition treated in hospital (Hospitalo Diagnosis = HD) and the underlying cause of death $\frac{\mathrm{O}}{\mathrm{O}}$ coded from the Death Certificate (DC). The proportion of cases in which the HD code was differento from the DC code varied markedly with the diagnosis. Where the HD was Malignant Disease only 11 per cent. discrepant codings occurred, whilst $55^{\circ}$ per cent. of HD codings for Pneumonia showed discrepancies. Table I (opposite) shows the propor-? tion of discrepant codings for selected HDs.

Details of age, sex, social class, marital status, hospital, and specialty concerned, length of stay, and $\bigcirc$ whether or not an autopsy was performed were also available in the Record Linkage data. A significantly윽 higher proportion of discrepant codings was found $>$ with increasing age, for certain hospitals and special-․ㅡ. ties, and for increasing length of stay. Tables II to VN (opposite) give these findings. Performance of an autopsy, and the sex, social class, and marital status 0 of the deceased were not related to the discrepancy $\omega$ of the coding.

The discrepancies associated with an individuato hospital or the age of the deceased might be due to $\Phi$ the fact that the elderly suffer from those conditions? which are directly associated with discrepant codings 0 
TABLE I

COMPARISON OF CODING OF-(1) UNDERLYING CAUSE OF DEATH, (2) PRINCIPAL CONDITION TREATED IN HOSPITAL, BY SELECTED DISEASE GROUPS

\begin{tabular}{|c|c|c|c|c|c|c|}
\hline $\begin{array}{l}\text { Hospital Diagnosis } \\
\text { ICD Nos }\end{array}$ & $\begin{array}{c}\text { Malignant } \\
\text { Neoplasms } \\
\text { 140-205 } \\
\text { B } 19\end{array}$ & $\begin{array}{c}\text { Cerebrovascular } \\
\text { Disease } \\
\text { 330-334 } \\
\text { B 22 }\end{array}$ & $\begin{array}{c}\text { Arteriosclerotic } \\
\text { Heart Disease } \\
\qquad 20-422 \\
\text { B } 26\end{array}$ & $\begin{array}{c}\text { Other Diseases } \\
\text { of Heart } \\
430-434 \\
\text { B } 27\end{array}$ & $\begin{array}{c}\text { Pneumonia } \\
490-493 \\
\text { B } 31\end{array}$ & $\underset{\text { Diagnoses }}{\text { All }}$ \\
\hline $\begin{array}{l}\text { Percentage Death Certificate } \\
\text { Coding Different* }\end{array}$ & 11 & 18 & 18 & 75 & s5 & 43 \\
\hline Total & 269 & 157 & 121 & 53 & 91 & 1,216 \\
\hline
\end{tabular}

$x^{2}=151 \cdot 4 ;$ d. of f. $=4 ; P<0.0005$

* Codes in different diagnostic groups of ICD List B.

TABLE II

COMPARISON OF CODING OF-(1) UNDERLYING CAUSE OF DEATH, (2) PRINCIPAL CONDITION TREATED IN HOSPITAL, BY AGE

\begin{tabular}{l|c|c|c|c|c|c}
\hline $\begin{array}{l}\text { Age of } \\
\text { Deceased (yrs) }\end{array}$ & $0-39$ & $40-59$ & $60-69$ & $70-79$ & $80-89$ & $\begin{array}{c}\text { All } \\
\text { Ages }\end{array}$ \\
\hline $\begin{array}{l}\text { Percentage } \\
\text { Codings } \\
\text { Different* }\end{array}$ & 35 & 31 & 38 & 47 & 52 & 43 \\
\hline Total & 78 & 189 & 255 & 363 & 331 & 1,216 \\
\hline
\end{tabular}

$\chi^{2}=28 \cdot 5 ;$ d. of f. $=4 ; P<0.0005$

* Codes in different diagnostic groups of IDC List B.
TABLE V

COMPARISON OF CODING OF-(1) UNDERLYING CAUSE OF DEATH, (2) PRINCIPAL CONDITION TREATED IN HOSPITAL, BY LENGTH OF STAY

\begin{tabular}{l|c|c|c|c}
\hline $\begin{array}{l}\text { Length of Stay in } \\
\text { Hospital (days) }\end{array}$ & -49 & $50-$ & $90+$ & All Lengths of Stay \\
\hline $\begin{array}{c}\text { Percentage of Codings } \\
\text { Different* }\end{array}$ & 40 & 44 & 62 & 43 \\
\hline Total & 998 & 59 & 159 & 1,216 \\
\hline
\end{tabular}

$x^{2}=26.0 ;$ d. of $f .=2 ; P<0.0005$

- Codes in different diagnostic groups of ICD List B.

TABLE III

COMPARISON OF CODING OF-(1) UNDERLYING CAUSE OF DEATH, (2) PRINCIPAL CONDITION TREATED IN HOSPITAL BY TYPE OF HOSPITAL IN WHICH DEATH OCCURRED

\begin{tabular}{l|c|c|c|c|c|c|c|c}
\hline $\begin{array}{c}\text { Type of } \\
\text { Hospital }\end{array}$ & $\begin{array}{c}\text { Acute } \\
\text { Teaching }\end{array}$ & $\begin{array}{c}\text { Other } \\
\text { Teaching }\end{array}$ & $\begin{array}{c}\text { Acute Non- } \\
\text { Teaching }\end{array}$ & Cottage & Chronic & Psychiatric & Remainder & $\begin{array}{c}\text { All } \\
\text { Hospitals }\end{array}$ \\
\hline $\begin{array}{l}\text { No. of } \\
\text { Hospitals }\end{array}$ & 2 & 3 & 1 & 5 & 1 & 5 & 3 \\
\hline $\begin{array}{l}\text { Percentage } \\
\begin{array}{c}\text { Codings } \\
\text { Different* }\end{array}\end{array}$ & 34 & 43 & 37 & 49 & 60 & 96 & 38 & 43 \\
\hline Total & 513 & 292 & 154 & 103 & 58 & 80 & 16 & 1,216 \\
\hline
\end{tabular}

$x^{2}=121 \cdot 7 ; \mathrm{d}$. of $\mathrm{f} .=6 ; \mathrm{P}<0.0005$

* Codes in different diagnostic groups of ICD List B.

TABLE IV

COMPARISON OF CODING OF-(1) UNDERLYING CAUSE OF DEATH, (2) PRINCIPAL CONDITION TREATED IN HOSPITAL, BY SPECIALTY OF ADMISSION

\begin{tabular}{l|c|c|c|c|c|c|c|c|c}
\hline Specialty & $\begin{array}{c}\text { General } \\
\text { Medicine }\end{array}$ & $\begin{array}{c}\text { General } \\
\text { Surgery }\end{array}$ & $\begin{array}{c}\text { Traumatic } \\
\text { and } \\
\text { Orthopaedic } \\
\text { Surgery }\end{array}$ & $\begin{array}{c}\text { Tuberculosis } \\
\text { and Diseases } \\
\text { of the Chest }\end{array}$ & $\begin{array}{c}\text { Chronic } \\
\text { Sick }\end{array}$ & $\begin{array}{c}\text { General } \\
\text { Medical } \\
\text { Practitioner }\end{array}$ & $\begin{array}{c}\text { Mental } \\
\text { Illness }\end{array}$ & Remainder \\
Specialties \\
\hline $\begin{array}{c}\text { Percentage } \\
\text { Dodings }\end{array}$
\end{tabular}


and that patients with such diagnoses are admitted to certain hospitals. The codings were therefore examined within three separate diagnostic groups: cerebrovascular accidents (ICD 330-334), arteriosclerotic heart disease (ICD 420-422), and pneumonia (ICD 490-493). There were significant differences in the proportion of discrepant codings for different hospitals in all three diagnostic groups. Increasing age was not associated with any significantly increased proportion of discrepant codings in any of these three diagnostic groups.

Examination of a Sample of Hospital Notes

One way of elucidating the source of the discrepancies associated with indefinite diagnoses, prolonged stay in hospital, and with certain hospitals and specialties, is to examine the hospital notes of the patients concerned. It was decided. therefore, to select a random sample of the cases already discussed and to examine the original notes.

\section{MethoD}

A one in twelve random sample of 106 cases was drawn from the 1,216 deaths in hospital in the ORLS Study Area in 1962; it was possible to examine the records of 105 of them. Records of the final hospital admission and of previous admissions to that hospital were available. Records from other hospitals in the ORLS area to which the patient might have been admitted were not examined. If patients had been in such other hospitals, however, there was usually a summary covering the admission. It was felt that the records examined represented the written information available to the doctors who filled in the Hospital Diagnosis and the Death Certificates, though it was appreciated that the clinicians concerned might have had knowledge of other information not recorded in the notes, such as symptoms or physical signs present shortly before death. This point could not be checked.

The Hospital Diagnosis and Death Certificate wording (if it appeared in the notes) were covered up when the notes were examined. After reading all the information available, one of the authors* completed the pro forma shown in Appendix I, giving his interpretation of the following items:

(i) Principal condition treated.

(ii) Underlying cause, where different, from the principal condition treated.

(iii) Complications of the principal condition or underlying cause.

(iv) Other conditions present.

(v) Death certificate.

* $(87$ per cent. of the cases were reviewed by T.W.M., and 13 per cent. by M.R.A.)
The diagnoses on these forms were supplemented $\mathscr{C}$ by notes of the evidence on which they were based 3 (i.e. clinical grounds and investigations, including $\underset{\propto}{\mathbb{Q}}$ surgery and autopsy), and, on the basis of the type and amount of this evidence, each of the diagnoses $\vec{P}$ was rated on a 5-point scale of the degree of confi-o dence with which it was made. The criteria for each point were defined (Appendix II). In addition to the $\frac{\overline{\bar{T}}}{\text {. }}$ five diagnoses entered on the pro forma, a note was $\widetilde{Q}_{0}$ made of the evidence on which the diagnoses were based, with brief details of the investigations carried ${ }_{-}^{\text {s }}$ out. Whenever indicated, "Underlying cause, where?

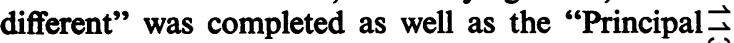
condition treated", and in complex cases a note was ${ }^{\omega}$ made of the other diagnoses which might be respon- $\bar{\alpha}$ sible. In this way it was hoped to avoid any undue $?$ rigidity which could inflate discrepancies artificially. $\stackrel{\sim}{-}$ All possible "Other conditions present" and "Com-plications" were recorded in a similar way.

These five items were then coded according to 0 current practice, and each of the two new codings for HD and DC obtained by this assessment was com- $c$ pared with the two corresponding original codings derived from the ORLS data. Comparison of simple numerical codes can give no more than a rough idea of the degree of agreement or discrepancy sin $\vec{\theta}$ differences of clinical opinion may assign a particular. condition to completely different groups in List B के the ICD. All the cases were therefore reviewed on clinical basis by both authors, their opinion of both the HD and DC being compared with the original coding; the following grades of agreement or $\frac{\circ}{\Phi}$ disagreement were established:

(i) Complete Agreement.-In these cases, diagnoses either agreed word for word, or were so similar that they were coded to exactly the same 3-digit figure according to standard procedure.

(ii) Reasonable Clinical Difference of Opinion.-This grade was applied to cases where different 3 . conclusions or diagnoses could be drawn from the $ᄋ$ clinical evidence. An example of this occurred in a patient with both chronic bronchitis and ischaemico heart disease. It was not possible to state with any certainty which condition was primarily responsible음 for hospital admission or for death. Also included $\frac{\bar{N}}{\mathrm{~N}}$ in this grade were several elderly patients, in whom $\%$ the presence of multiple pathology led to some N uncertainty.

(iii) Error.-This grade was used only when there was unequivocal evidence of a serious mistake in the wording of the "Principal Condition Treated" on the $\Phi$ In-Patient summary sheet, or of the "Underlying." Cause of Death", on the death certificate. The authors' 
confidence ratings (technically speaking!) were high in this grade, and cases in which decisions had to be made on the accuracy of conclusions reached from clinical evidence alone were not included in it. Most cases were assigned to it because of the omission of an obvious underlying cause, or because a complication, or a concomitant but quite unrelated condition to that being treated or causing death had been entered. Thus "jaundice" as a hospital diagnosis as well as a cause of death, in a case with full clinical, surgical, and autopsy evidence of gall-stones as the reason for hospital admission, treatment, and death, was treated as a double error. Two other cases, in which urinary infection was given as the cause of death when fully documented evidence for benign prostatic hyperplasia existed, were treated as errors. When there was any doubt a coding was included under "Reasonable Clinical Difference" rather than "Error". The original codings were only labelled as "Errors" where the authors considered that other doctors would agree with such a decision and that there was no evidence for suggesting that the discrepancy was due to differences in clinical judgement.

\section{RESULTS}

Table VI shows overall results for Hospital Diagnosis and Death Certificate. 37 "Errors" were made out of 210 possibilities, errors in $\mathrm{HD}$ accounting for fourteen (13 per cent.) and in DC for 23 (22 per cent.). The difference in errors between $\mathrm{HD}$ and $\mathrm{DC}$ is not significant.

TABLE VI

INDEPENDENT ASSESSMENT OF THE ORIGINAL DIAGNOSIS - (1) FOR THE UNDERLYING CAUSE OF DEATH (FROM THE DEATH CERTIFICATE), (2) FOR THE PRINCIPAL CONDITION TREATED IN HOSPITAL (FROM THE HOSPITAL SUMMARY SHEET)

\begin{tabular}{|c|c|c|c|c|}
\hline \multirow{2}{*}{$\begin{array}{c}\text { Diagnosis } \\
\text { on } \\
\text { Original } \\
\text { Documents }\end{array}$} & \multicolumn{3}{|c|}{ Independent Assessment } & \multirow[b]{2}{*}{ Total } \\
\hline & $\begin{array}{l}\text { Complete } \\
\text { Agreement }\end{array}$ & $\begin{array}{c}\text { Reasonable } \\
\text { Clinical } \\
\text { Difference }\end{array}$ & Error & \\
\hline $\begin{array}{l}\text { Principal } \\
\text { Condition } \\
\text { Treated in } \\
\text { Hospital }\end{array}$ & 56 & 35 & 14 & 105 \\
\hline $\begin{array}{c}\text { Underlying } \\
\text { Cause of } \\
\text { Death }\end{array}$ & 56 & 26 & 23 & 105 \\
\hline
\end{tabular}

$\chi^{2}=3.5 ;$ d. of f. $=2 ; P<0.2$.

Table VII shows how the discrepancies were distributed in the sample of 105 cases, when these are grouped according to the level of agreement between the coding of the original ORLS, HD, and DC. There were 63 cases with the two original codings in the same diagnostic group; the independent assessment
TABLE VII

INDEPENDENT ASSESSMENT OF THE ORIGINAL DIAGNOSIS FOR THE UNDERLYING CAUSE OF DEATH FROM THE DEATH CERTIFICATE, AND FOR THE PRINCIPAL CONDITION TREATED IN HOSPITAL, FROM THE HOSPITAL SUMMARY SHEET, TABULATED AGAINST THE LEVEL OF AGREEMENT BETWEEN THE TWO ORIGINAL CODINGS

\begin{tabular}{|c|c|c|c|c|}
\hline \multicolumn{2}{|c|}{ Independent Assessment } & \multicolumn{2}{|c|}{$\begin{array}{c}\text { Comparison of Original } \\
\text { Codings }\end{array}$} & \multirow{2}{*}{ Total } \\
\hline $\begin{array}{c}\text { Principal } \\
\text { Condition } \\
\text { Treated }\end{array}$ & $\begin{array}{c}\text { Underlying } \\
\text { Cause }\end{array}$ & Same* & Differentt & \\
\hline \multirow{3}{*}{$\begin{array}{l}\text { Complete } \\
\text { Agreement }\end{array}$} & $\begin{array}{c}\text { Complete } \\
\text { Agreement }\end{array}$ & 39 & 1 & 40 \\
\hline & $\begin{array}{c}\text { Reasonable } \\
\text { Clinical } \\
\text { Difference }\end{array}$ & 4 & 2 & 6 \\
\hline & Error & 1 & 9 & 10 \\
\hline \multirow{3}{*}{$\begin{array}{l}\text { Reasonable } \\
\text { Clinical } \\
\text { Difference }\end{array}$} & $\begin{array}{r}\text { Complete } \\
\text { Agreement }\end{array}$ & 2 & 9 & 11 \\
\hline & $\begin{array}{l}\text { Reasonable } \\
\text { Clinical } \\
\text { Difference }\end{array}$ & 12 & 6 & 18 \\
\hline & Error & 0 & 6 & 6 \\
\hline \multirow{3}{*}{ Error } & $\begin{array}{l}\text { Complete } \\
\text { Agreement }\end{array}$ & 0 & 5 & 5 \\
\hline & $\begin{array}{c}\text { Reasonable } \\
\text { Clinical } \\
\text { Difference }\end{array}$ & 0 & 2 & 2 \\
\hline & Error & 5 & 2 & 7 \\
\hline \multicolumn{2}{|c|}{ Total } & 63 & 42 & 105 \\
\hline
\end{tabular}

* Same = 3-digit Code for Principal Condition Treated and Underlying Cause of Death within same diagnostic group of ICD List B.

+ Different $=$ Codes in different diagnostic groups of ICD List B. $\chi^{2}=44.5 ;$ d. of $f .=2 ; P<0.0005$.

agrees completely in 39 cases, and in a further eighteen cases one or both items were classed as "Reasonable Clinical Difference" $(4+2+12)$. In five of the remaining six cases there was considered to be a double error (e.g. both original entries were coded to Carcinoma of the Cervix, but there was unequivocal surgical and histological proof that the growth was a Carcinoma of the Body of the Uterus); in the sixth case there was an error in the DC (a patient dying from Carcinoma of the Stomach, shown at operation and proved on histology, in which HD was coded to this condition but the DC gave Carcinoma of the Pancreas).

There were 42 cases in which the ORLS original HD and DC codes were in different diagnostic groups, and this reflected the clinical picture in only one case, i.e. death was due to a cause unrelated to the Principal Condition Treated (a patient who died from a myocardial infarction after recovery from a cholecystectomy). In seventeen cases $(2+9+6)$ the discrepancies were minor, and involved genuine differences of clinical opinion for one or both items (as in a patient with chronic bronchitis and ischaemic 
heart disease, in whom it was arguable which condition was mainly responsible for admission to hospital and for death). Elderly patients with multiple pathology also contributed significantly to this group. In the remaining 24 cases $(9+6+5+2+2)$ there seemed to be an error in one or both entries on the original documents (as in the omission of cirrhosis of the liver, as the underlying cause of ruptured oesophageal varices). Thus the proportion of "errors" found was significantly lower amongst cases in which the two original entries were coded within the same diagnostic group $(P<0.0005)$.

In the authors' assessment, there were only eight cases ( 7.2 per cent.) in which it was thought that HD and DC should not agree (five of the eight cases were patients in long-stay hospitals, where it might reasonably have been expected that a number of deaths would occur from a condition unrelated to that which originally led to hospital admission.) This contrasted sharply with the original ORLS codes in which different codes were found in 42 cases ( 40 per cent.).

The hospitals in which the patients died comprised several in a Teaching group and several non-teaching hospitals, among which were several cottage hospitals staffed entirely by general practitioners, a psychiatric hospital, a rehabilitation hospital, and a general hospital with a geriatric wing. A significantly higher proportion of errors occurred in the non-teaching hospitals. There was a suggestion (not statistically significant) that in the cottage hospitals, where one doctor originated both codes, there was a higher proportion of cases with agreement between those codes, and the independent assessment changed relatively few of these.

In this sample study, age appeared to have no effect on the number of errors, but this is probably due to the small numbers involved. As anticipated from earlier findings (Table I), it was found that for certain disease groups (e.g. neoplasms) there were substantially fewer errors.

The death certificates on which the ORLS codings were based had not been corrected for unexpected autopsy findings which became available after the original certificate was signed. Autopsies were performed in 55 ( 52 per cent.) of our cases, but in only two of them were such unexpected findings encountered. In only one case was there a real possibility that autopsy findings, if they had been available before the time of signing the DC, would have altered the wording; if the certificate had incorporated the autopsy findings, it would have been classed as "complete agreement" instead of being classified as "error". It is therefore apparent that the use of uncorrected Death Certificates caused only a very small overestimation of the number of errors (i.e. 1 in 22).

\section{Discussion}

The comparison of the coding of the "Principal Condition Treated in Hospital" with the "Under- $\frac{}{O}$ lying Cause of Death" for 1,216 patients dying in $\frac{\bar{\sigma}}{\bar{p}}$ hospital showed discrepancies in 39 per cent. of $\vec{\phi}$ cases. The association of a substantial rate of $\varrho$ discrepancies with rather indefinite diagnoses, with के prolonged stay in hospital, and with certain hospitals $\vec{\circ}$ and specialties, suggests that the discrepancies are $\overrightarrow{-}$ not random occurrences. Nor did the errors in the $\overrightarrow{\mathrm{s}}$ entries for both the HD and the DC detected in the sample study appear to be random, though $\frac{\AA}{5}$ the number of case records examined was small. in It is difficult to assess with any degree of confidence ${ }_{-}^{-}$ the net effect such errors would have on a national $\vec{\sim}$ scale, but they would introduce bias into the statis- $N$ tics. The proportion of errors is too large to ignore and the implications of these errors could be serious, $\vec{c}$ since the "Hospital In-Patient Inquiry Reports" and the mortality figures issued by the Registrar General are amongst the most important sources of information on the nation's health. We have no reason to $\vec{\theta}$ believe that the ORLS area is any less accurate the the rest of the country in respect of the figures It $^{-}$ contributes to these sources; in fact, the specialo circumstances of the area almost certainly ensure that it is better than average.

This study indicates that statistics in the "Hospital\% In-Patient Inquiry Reports", which are based on the codings of a 10 per cent. sample of hospital dis- $\overrightarrow{\overrightarrow{0}}$ charges, including deaths, require interpreting with 3 caution, since on a sample of records apparently? major errors in the completion of the HD (Principalo Condition Treated) were detected in 13 per cent. of $\bar{\alpha}$. cases. It showed similar errors in 22 per cent. of the $\overline{-}$ DC, thus emphasizing that the entry on the certificate often does not accurately reflect the clinician's real opinion of the underlying cause of death and mayo frequently be erroneous. These are conservative $₹$ estimates of the total number of diagnoses which are윽 not recorded as precisely as possible.

The study suggests that the HD refiects the under-을. lying cause of death more accurately than the $\mathrm{DC}, \mathrm{N}$ although the difference in the number of errors between the two did not reach the conventional level 0 of significance.

The proportion of such errors was much highero when the two original ORLS codes disagreed, ando this fact, if it is a general one, could provide a valu- $-\frac{\bar{\phi}}{\mathrm{T}}$ able way of indicating where errors are to be found, and which cases in particular should be checked foro 
accuracy of certification and coding by inquiry to the certifier. In particular, it seems that care should be taken to see that "Other Conditions Present" (but relevant to the main illness) and "Complications" are not incorrectly used in place of the "Principal Condition Treated", or the "Underlying Cause of Death".

A high degree of accuracy in this field is of advantage to clinicians, for example, in providing a valid basis for Clinical Research, as well as to those concerned with Public Health and Medical Statistics; but the value achieved is governed almost exclusively by those who initiate the documents on which codings are based-that is, junior and middle-grade hospital staff in the present instance. The registrar is usually the person who completes the HD or "Principal Condition Treated"; the house officer usually completes the "Death Certificate". This involvement of two different people is in itself a probable source of error. But further inaccuracy is undoubtedly introduced into each item by a lack of appreciation by those concerned of what is involved in making a correct entry, and what in turn depends on this entry. This is largely a matter for education, probably during the preregistration period, but at present few would disagree that accurate certification is very low on the list of priorities of a busy house officer, and that the same kind of consideration applies to a registrat filling in the summary sheets of a pile of hospital notes.

Further work is needed in the field of accuracy of certification. It would be particularly well worth while to investigate sources of error in the case of patients discharged from, and not dying in, hospitals. More attention should be paid to the problem of accuracy in diagnosis and certification in elderly patients, where multiple pathology makes the choice of one HD or DC difficult or even inappropriate. It may even be that a new system is necessary for collecting meaningful data in these circumstances.

\section{SUMMARY}

The "Principal Condition Treated" in hospital, as stated on the summary sheet of the In-Patient notes, and the "Underlying Cause of Death" on the death certificate, were compared for 1,216 patients dying in thirty hospitals of the Oxford Record Linkage Study area in 1962. In 39 per cent. of the cases, the two diagnoses differed to such an extent that they had to be coded to different groups of List B of the International Statistical Classification of Disease. Discrepancies occurred more often in certain classes of disease (being common when the entry on either document referred to "Pneumonia", and least common with "Malignant Neoplasms"); among the aged; in certain specialties and hospitals; and with increasing length of stay in hospital.

A one in twelve random sample of the 1,216 cases was drawn, and the main clinical documents were examined. The original codes for the Hospital Diagnosis and Death Certificate differed in 42 (40 per cent.) of the 105 cases. In one of these 42 cases, the discrepancy in coding reflected the clinical picture, i.e. death was due to a cause unrelated to the "Principal Condition Treated". In seventeen cases, the discrepancies were minor, and involved genuine differences of medical opinion. Elderly patients with multiple pathology also contributed significantly to this group. In just over half the cases there seemed to be an error in one or both entries on the original documents.

In some cases there were double errors. In all, we found errors in fourteen entries (13 per cent.) of "Principal Condition Treated", and in 23 entries (22 per cent.) of "Underlying Cause of Death", making a total of 37 errors in $210(2 \times 105)$ entries. There were fewer errors in cases of malignant neoplasms than in other classes of disease, and fewer in teaching than in non-teaching hospitals. Age was not a factor here. Nearly all the errors were due to the entering of a complication, or of another condition incidental to the main illness, as the "Principal Condition Treated" or the "Underlying Cause of Death".

The proportion of errors in entries on the InPatient summary sheet to describe the "Principal Condition Treated", if found on a national scale, would seriously lessen the validity of the "Hospital InPatient Inquiry" statistics. Similarly, since about half of all deaths occur in hospital, a national level of errors in Death Certificates comparable to that found in this study would seriously reduce the value of the Registrar General's figures for Causes of Death.

Mortality and morbidity data continue to be used in an attempt to identify factors associated with disease; random error in the data tends to diminish such associations whilst bias may obscure any significant aetiological relationships. Increasing activity in health planning leads to a growing demand for information which can help to make the plans realistic and at a later stage be used to evaluate the programmes. For this purpose it is desirable to have accurate statistics.

We are most grateful to Dr E. D. Acheson, Medical Director of the Oxford Record Linkage Study, for allowing us access to the material from the Linkage Study and for encouraging us to analyse it. We thank Prof. J. N. Morris, who gave us much advice, and the 
colleagues in our Unit and Dr A. S. Fairbairn, who all read a draft of the paper and offered helpful suggestions.

This study could not have been made without the co-operation of the Medical Records Officers concerned, to whom we are greatly indebted.

\section{REFERENCES}

Acheson, E. D. (1964). Brit. J. prev. soc. Med., $18,8$. Alderson, M. R. (1965). M.D. Thesis, London University. Cabot, R. C. (1912). J. Amer. med. Ass. 59, 2295.

Dorn, H. F. and Horn, J. I. (1941). Amer.J. Hyg., 34, 12. Farr, W. (1839). In "First Annual Report of the RegistrarGeneral of Births, Deaths, and Marriages, in England"?
p. 93. H.M.S.O., London.

Heasman, M. A. (1962). Proc. roy. Soc. Med., 55, 733.

Jackson, H. (1896). Boston med. surg. J., 134, 501.

MacDonald, E. J. (1938). Amer. J. publ. Hlth, 28, 818.

McKenzie, A. (1956). Brit. med. J., 2, 204.

Moriyama, I. M., Baum, W. S., Haenszel, W. M., and Mattison, B. F. (1958). Amer. J. publ. Hlth, 48, 1376.

Morris, J. N. (1964). "Uses of Epidemiology", 2nd ed을 Livingstone, London.

Registrar General (1954). "Statistical Review of Englando and Wales, 1950. Text, Medical", p. 196. H.M.S.O. London.

Stocks, P. (1935). Lancet, 2, 386.

Swartout, H. O. (1934). New Engl. J. Med., 211, 539.
HOSPITAL DIAGNOSIS

MAIN DIAGNOSIS AT DISCHARGE

I (a) Principal Condition Treated (or found at investigation)

\begin{tabular}{|l|l|l|l|}
\hline 15 & 16 & 17 & 18 \\
\hline & & & \\
\hline
\end{tabular}

19 Evidence for Diagnosis

1 History

2 History + Clinical Examination

$3 x$ ray

4 Chemical Pathology

5 Bacteriology

6 Electrocardiogram

7 Haematology

8 Histology

9 Endoscopy

0 Specify

$x$ None

\section{APPENDIX I}

PRO FORMA USED FOR SUMMARY OF NOTES

20

1 Surgery

2 Surgery + Autopsy

3 Autopsy Expected Findings

4 Autopsy Unexpected Findings

5 Clinical Investigation

6 Investigation without Clinical Examination

7 Specify

8 Specify

9 None
21 Assessment of Diagnosis

1 Confident

2 Probable

3 Supported

4 Possible

5 Guess

NOTE: Similar sheets were completed for: I (b) Underlying Condition or Cause where different.

II Principal Complications of I (a), I (b).

III Other Conditions Present. Death Certificate. 


\section{APPENDIX II \\ CONFIDENCE RATING}

The information available in support of the diagnosis has been graded by the authors on a five-point scale, allocating each case to one of the following five categories: Confident, Probable, Supported, Possible, or Guess.

Though this is essentially a subjective grading based on an appreciation of the weight of medical data supporting the diagnosis, some degree of objectivity was introduced by following basic rules for grading the information.

"Supported" was applied to a case in which the history and clinical findings were adequate in detail and agreed closely with that usually found in cases with such a diagnosis; the case was considered to be supported by a confident clinical picture of the disease.

Where appropriate investigations had been performed and they confirmed the clinical diagnosis the case was graded as "Probable" or "Confident", depending on the type of investigation. Thus, following laparotomy for a neoplasm of the stomach, the case would be graded as "Probable" on the surgeon's macroscopic findings, or as "Confident" if resection of the primary neoplasm had been carried out and confirmatory histology was available.

Where there was little history and no investigations, a diagnosis would be graded as "Possible".

Where there were no clinical details of the course of the fatal illness and no autopsy, the diagnosis was graded as a "Guess".

Where the investigations were at variance with the clinical findings or history, the authors endeavoured to allocate the most likely diagnosis, though necessarily grading the case in one of the low confidence ratings. 